\title{
Plutonium Immobilization Project Development and Testing Technical Project Office Quality Assurance Program Description
}

J. M. Ziemba

T. H. Gould, Jr.

L. M. MacLean

June 16, 1999

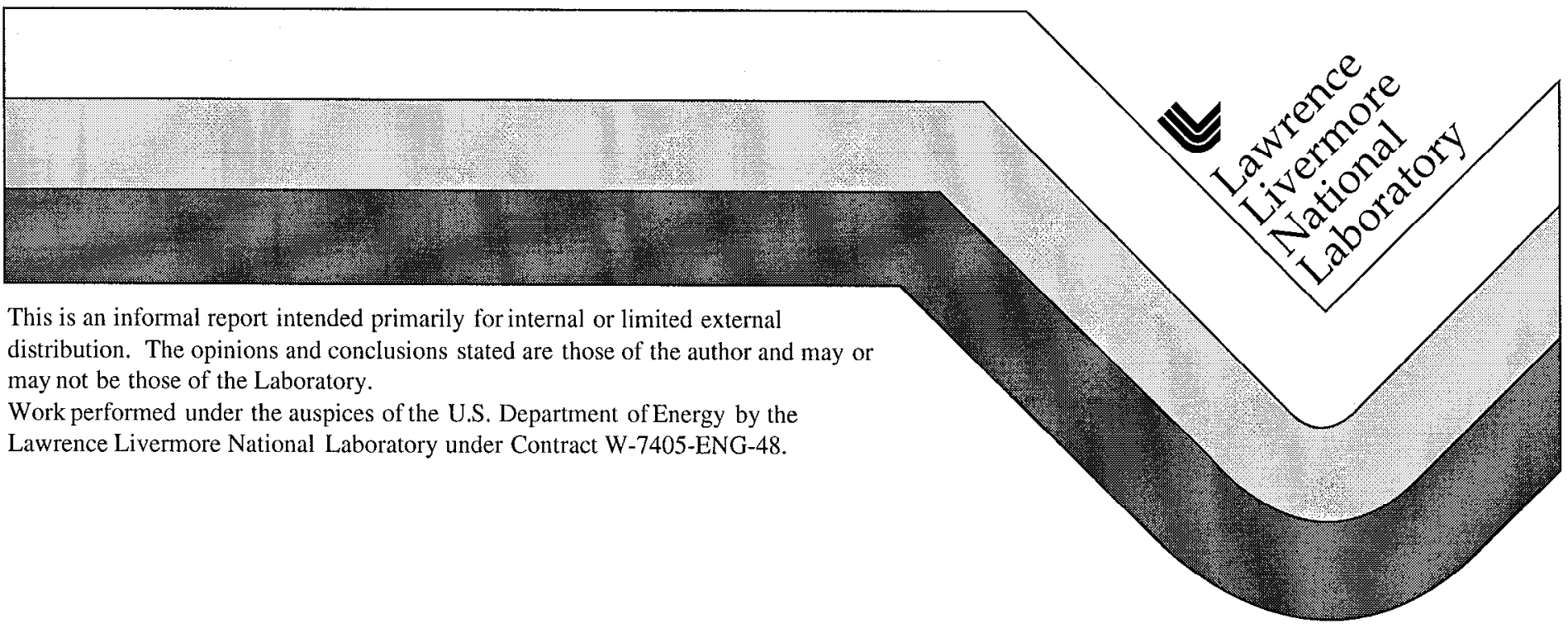




\section{DISCLAIMER}

This document was prepared as an account of work sponsored by an agency of the United States Government. Neither the United States Government nor the University of.California nor any of their employees, makes any warranty, express or implied, or assumes any legal liability or responsibility for the accuracy, completeness, or usefulness of any information, apparatus, product, or process disclosed, or represents that its use would not infringe privately owned rights. Reference herein to any specific commercial product, process, or service by trade name, trademark, manufacturer, or otherwise, does not necessarily constitute or imply its endorsement, recommendation, or favoring by the United States Government or the University of California. The views and opinions of authors expressed herein do not necessarily state or reflect those of the United States Government or the University of California, and shall not be used for advertising or product endorsement purposes.

This report has been reproduced directly from the best available copy.

Available to DOE and DOE contractors from the

Office of Scientific and Technical Information

P.O. Box 62, Oak Ridge, TN 37831

Prices available from (423) 576-8401

Available to the public from the

National Technical Information Service

U.S. Department of Commerce

5285 Port Royal Rd.,

Springfield, VA 22161 


\section{PLUTONIUM IMMOBILIZATION PROJECT \\ DEVELOPMENT AND TESTING \\ TECHNICAL PROJECT OFFICE \\ QUALITY ASSURANCE \\ PROGRAM DESCRIPTION}

June 16, 1999

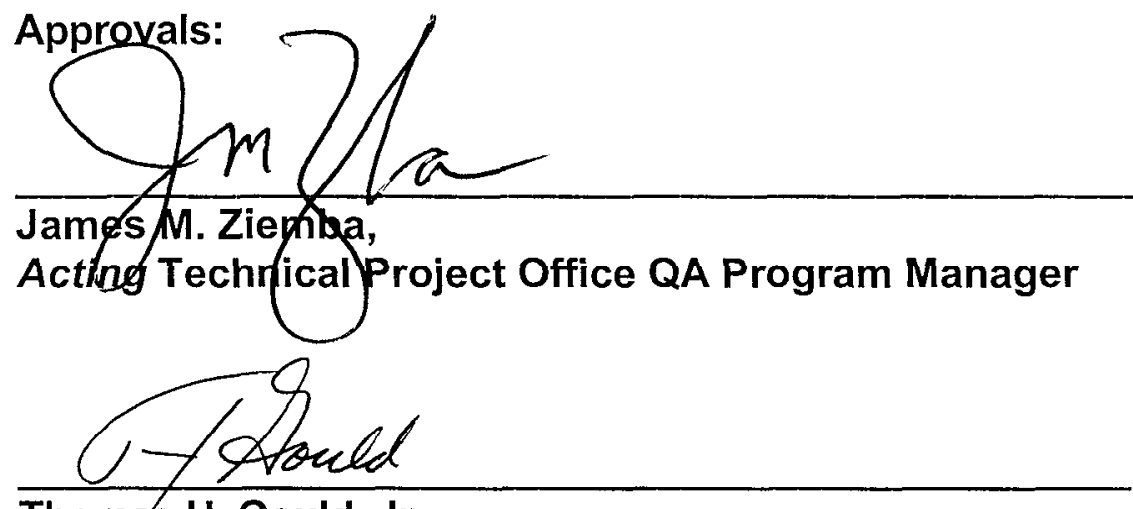

Thomas H. Gould, Jr.,

Technical Manager

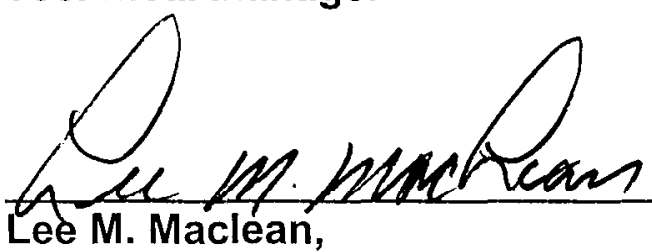

$\frac{6-16-99}{\text { Date }}$

PIP D\&T Lawrence Livermore National Laboratory

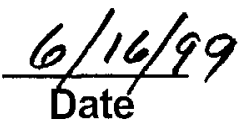

Fissile Materials Disposition Program Manager 
TABLE OF CONTENTS

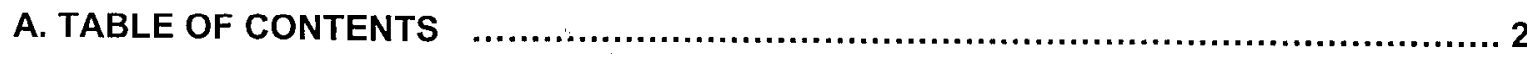

B. INTRODUCTION AND MANAGEMENT'S QUALITY ASSURANCE POLICY

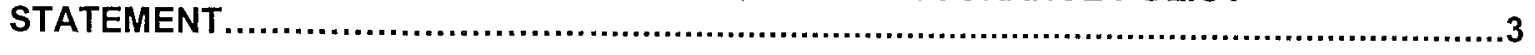

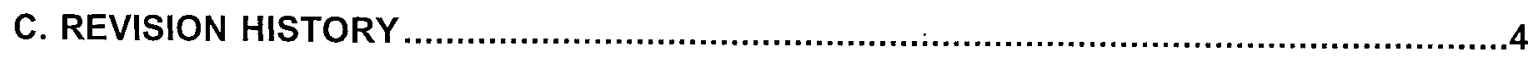

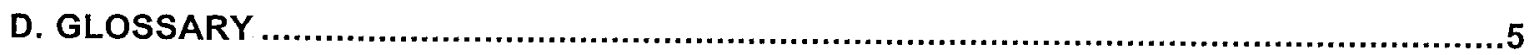

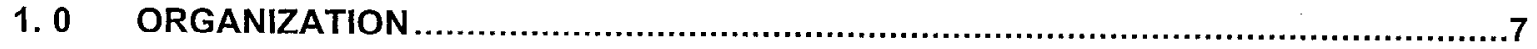

2. 0 QUALITY ASSURANCE PROGRAM........................................................ 14

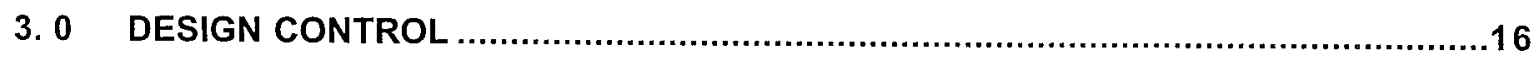

4. $0 \quad$ PROCUREMENT DOCUMENT CONTROL .......................................................18

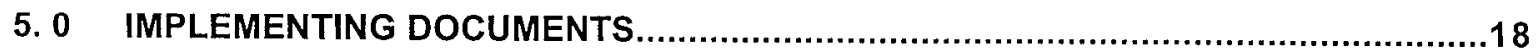

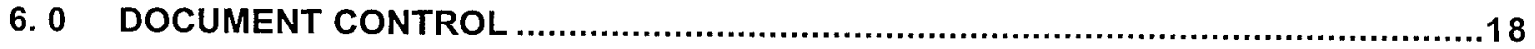

7. 0 CONTROL OF PURCHASED ITEMS AND SERVICES ..................................19

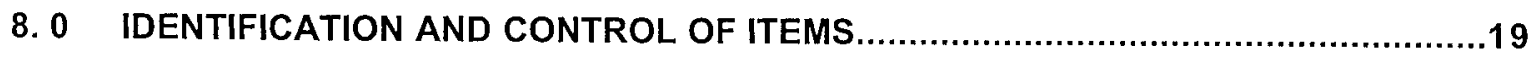

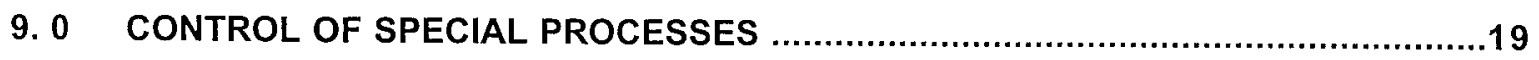

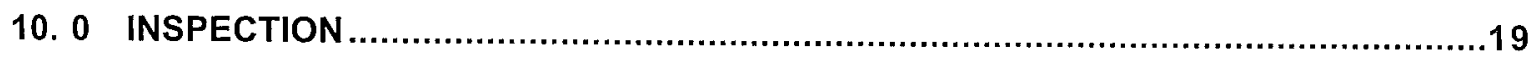

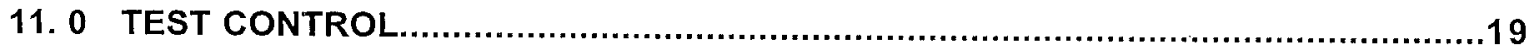

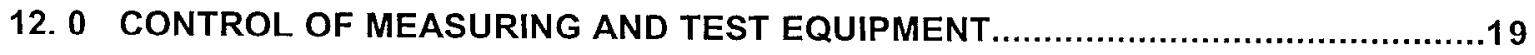

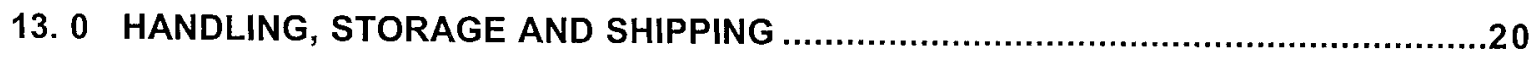

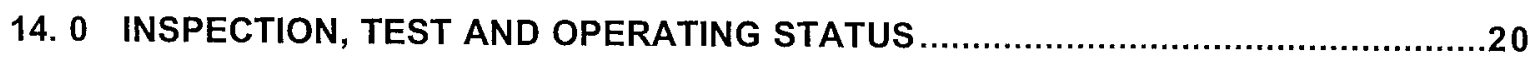

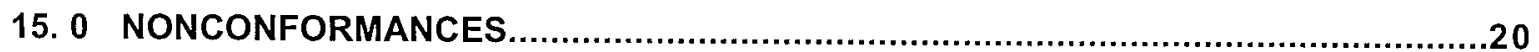

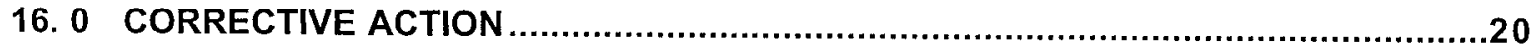

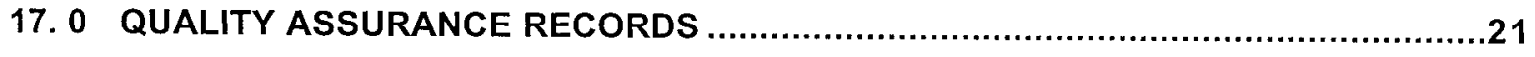

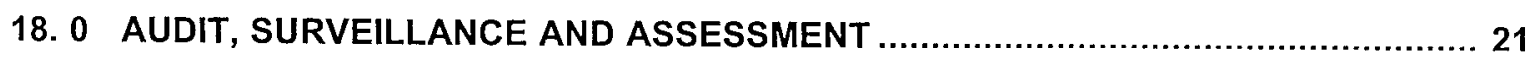

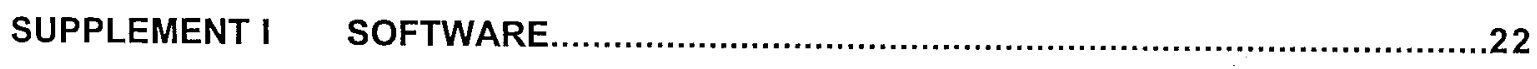

SUPPLEMENT II $\quad$ SAMPLE CONTROL .............................................................22

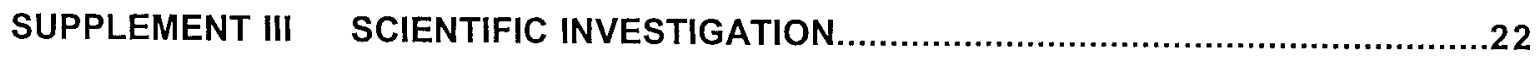

SUPPLEMENT IV FIELD SURVEYING.........................................................22

SUPPLEMENT $V$ CONTROL OF THE ELECTRONIC MANAGEMENT OF DATA ............22

APPENDIX A HIGH-LEVEL WASTE FORM PRODUCTION...................................23

APPENDIX B STORAGE AND TRANSPORTATION .......................................23

APPENDIX C MINED GEOLOGIC DISPOSAL SYSTEM ....................................23 


\section{PLUTONIUM IMMOBILIZATION PROJECT DEVELOPMENT AND TESTING QA PROGRAM DESCRIPTION}

\section{B. INTRODUCTION AND MANAGEMENT'S QUALITY ASSURANCE POLICY STATEMENT}

The Plutonium Immobilization Project (PIP) is one of several fissile materials disposition projects managed by the Department of Energy (DOE) Office of Fissile Materials Disposition (OFMD). The PIP is expected to evolve from the current Development and Testing (D\&T) effort, to design, to construction, and finally to operations. Overall management and technical management of the D\&T effort resides at the Lead Laboratory, Lawrence Livermore National Laboratory (LLNL), through the LLNL Manager, Fissile Materials Disposition Program (FMDP). Day to day project activities are managed by the D\&T Technical Project Office (TPO), which reports to the LLNL Manager, FMDP. The D\&T TPO consists of the Technical Manager, the TPO Quality Assurance (QA) Program Manager, and TPO Planning and Support Staff.

This Quality Assurance Program Description (QAPD) defines the QA policies and controls that will be implemented by these TPO personnel in their management of D\&T activities. This QAPD is consistent with and responsive to the Department of Energy Fissile Materials Disposition Program Quality Assurance Requirements Document (FMDP QARD). As the Project and upper level requirement's documents evolve, this QAPD will be updated as necessary to accurately define and describe the QA Program and Management of the PIP.

The TPO has a policy that all development and testing activities be planned, performed and assessed in accordance with its customer's requirements, needs and expectations, and with a commitment to excellence and continuous improvement.

The TPO QAPD describes implementation requirements which, when completed, will ensure that the project development and testing activities conform to the appropriate $Q A$ requirements. For the program to be effective, the TPO QA Program Manager will ensure that each site participating in D\&T activities has developed a QAPD, which meets the customer's requirements, and has a designated quality leader in place. These customer requirements, needs, and expectations are defined in the FMDP QARD.

Compliance with the TPO QAPD and procedures will ensure that our D\&T deliverables meet the high standards of quality expected by the Department of Energy. 


\section{REVISION HISTORY}

\begin{tabular}{|c|c|c|}
\hline REVISION & DESCRIPTION OF REVISION & REVISION DATE \\
\hline 0 & $\begin{array}{l}\text { Initial issue of the Quality Assurance } \\
\text { Plan, PIP-98-023. }\end{array}$ & April 30, 1998 \\
\hline 1 & $\begin{array}{l}\text { Revised to QAPD format based } \\
\text { on DOE OFMD comments. No revision } \\
\text { bars used. Supersedes QA Plan } \\
\text { PIP-98-023 dated April 30, } 1998 \text {. }\end{array}$ & February 9, 1999 \\
\hline 2 & $\begin{array}{l}\text { Revised to meet FMDP QARD, Rev } 0 \\
\text { and incorporate DOE MD HQ } \\
\text { comments. Supersedes QAPD } \\
\text { PIP-98-023 Rev } 1 .\end{array}$ & April 2, 1999 \\
\hline 3 & $\begin{array}{l}\text { Revised to incorporate DOE OFMD } \\
\text { Comments. No revision bars used. }\end{array}$ & June 16, 1999 \\
\hline
\end{tabular}




\section{GLOSSARY}

Activity: A directed process working toward an objective. Activities include programmatic functions; facility operations, scientific research experiments; development of prototype and test equipment and software, chemical processes; accelerator, computer and facility operations; and all forms of technical services and administrative functions.

Activity leader: The line manager responsible for an activity or group of activities covered by a QA plan. The activity leader may be at any level within the organization. Examples of activity leaders may include supervisors, division leaders, facility managers, group leaders, project leaders, project engineers, principal investigators, and lead experimenters.

Affected organizations: An organization performing Program work subject to QARD requirements whose organizational relationships are defined in D\&T Project documents. The Plutonium Immobilization Project sites are affected organizations.

Assessment: An audit, quality surveillance, readiness review or management self-assessment performed by D\&T Project personnel and/or other independent quality professionals and technical specialists in order to verify and validate quality performance, evaluate the level of excellence an organization is providing and/or recommend quality improvement actions.

Document: Recorded information that describes, defines, specifies, reports, certifies, requires, or provides data or results. This information can be written, pictorial, photographic, or computer media form.

D\&T: Development and Testing

D\&T TPO or TPO: Development and Testing Technical Project Office - The management functions responsible for the overall performance of the D\&T effort to the quality, cost and schedule requirements.

ES\&H: Environment, Safety \& Health. Generally includes activities designed to protect the environment, ensure the safety and health of employees and the public, and to meet regulatory requirements in these areas.

FMDP QARD: DOE Quality Assurance Requirements Document for the Fissile Materials Disposition Program.

Graded approach: A method that provides for application of management controls commensurate with the consequences and probability of failure risk. 
Implementing procedure: A document that specifies or describes how an activity is to be performed.

Inspection: A quality assurance program verification that is used to verify whether an item conforms to specified technical criteria. An inspection is an examination or measurement to verify whether an item or process meets specified requirements.

Plan: A scheme or method formulated beforehand, for performing a specific activity.

Policy: A basic guiding principle provided by management.

QA: Quality Assurance.

QA Plan: A facility-, site-, or activity-level document that details the implementation of QA. The QA Plan may be referenced in other facility-, site- or activity-level documents.

Quality: The degree to which an item or process meets or exceeds the user's requirements and expectations.

Record: A completed document or other media that provides objective evidence of an item or process.

Risk: A quantitative or qualitative expression of possible loss, which considers both the probability of an occurrence and the consequences of that event.

Technical Project Office Quality Assurance (TPO QA): The lead quality assurance organization for the D\&T.

Testing (in an experiment or laboratory): The determination of the response of a material, item or system by subjecting it to a set of physical, chemical environmental, or other conditions.

Validation: An activity that demonstrates that an item or process will perform under conditions of actual use and satisfy requirements of the user.

0333P: DOE/RW 0333P Quality Assurance Requirements and Description Document for the Civilian Radioactive Waste Management Program. 


\subsection{ORGANIZATION}

\subsection{GENERAL}

This section describes the QA implementation requirements for creating and maintaining an organizational structure to implement the Quality Assurance Program for the Technical Project Office related to the Development and Testing effort. This section also provides a description of the TPO internal organization, external interfaces, organizational structure and responsibilities for the scope of work.

\subsection{ORGANIZATIONAL STRUCTURE}

The Development and Testing (D\&T) part of the Plutonium Immobilization Project is organized such that LLNL has overall management responsibility and is the lead technical organization. The LLNL Manager, Fissile Materials Disposition Program (FMDP), is the position that maintains this overall responsibility. Besides Plutonium Immobilization Development and Testing, the LLNL Manager, FMDP is responsible the Pit Disassembly and Conversion activities and Fissile Materials International Programs at LLNL. These two additional activities are separate from the PIP D\&T effort and not discussed further in this QAPD. The Immobilization Technical Project Office, which reports to the LLNL Manager, FMDP, is comprised of the Technical Manager, the TPO QA Program Manager, and the TPO Planning and Support Staff.

Figure 1 shows the functional D\&T organization. The shaded boxes denote the Technical Project Office functions and the non-shaded boxes denote the balance of the organizational structure and other interfacing organizations.

The TPO QA Program Manager is the quality assurance lead for the D\&T activities. The position is responsible for quality assurance activities at the Technical Project Office level and for oversight functions at the Participating Lab level.

\subsection{DUTIES AND RESPONSIBILITIES}

The duties and responsibilities of the Technical Project Office are described in this QAPD. Specific duties and responsibilities of these D\&T management positions responsible for achieving and maintaining quality are included in quality implementing procedures.

The major participants in the D\&T effort and their primary technical responsibilities are listed below. A number of responsibilities are shared among the participating organizations. 
Lawrence Livermore National Laboratory (LLNL) - overall D\&T management responsibility and technical lead, form characterization and qualification, ceramic form development lead, process/equipment development with plutonium, and process systems testing and validation for both conversion and immobilization.

Westinghouse Savannah River Company (WSRC) and WSRC's Technology Center (SRTC) - partners with LLNL in several activities including form qualification and repository interface, form development, process/equipment development activities, process/product validation testing with plutonium, and technology transfer to the plant, and full scale canister pour experiments.

Argonne National Laboratory (ANL) - properties/characterization of immobilization forms, form development and performance testing.

Pacific Northwest National Laboratory (PNNL) properties/characterization of immobilization forms, performance testing and possibly full-scale cold canister pour experiments.

The following are the general quality related responsibilities of the D\&T personnel:

- Quality shall be achieved and maintained by the Line Organization.

- Verification of the quality of the work shall be conducted by persons or organizations not directly responsible for performing the work. This verification shall be performed internal to the D\&T and may also be verified by outside organizations.

- Differences of opinion involving QA Program requirements shall be brought to the attention of the appropriate management and, if not resolved, shall be elevated progressively to the highest levels of management at the Department of Energy.

\subsubsection{LLNL Manager, Fissile Materials Disposition Program}

The LLNL Manager, Fissile Materials Disposition Program (FMDP), has overall responsibility for management of the Plutonium Immobilization Project Development and Testing effort. Included in this authority is responsibility for allocating appropriate resources and establishment of the QA Program associated with D\&T activities. Conflicts and disputes involving quality arising from a difference of opinion between QA personnel and others that cannot be 
resolved by the TPO QA Manager and D\&T Technical Manager shall be referred to the LLNL Manager, FMDP, for final resolution as appropriate. The LLNL Manager, FMDP, may consult with the Department of Energy (DOE) Office of Fissile Materials Disposition (OFMD) for help in resolving these disputes.

Specific responsibilities include:

- approving this QAPD, QA Requirements Matrix, and maintaining an organizational structure and environment conducive to the effective implementation of the D\&T QA Program;

- planning of resources to ensure the satisfactory execution of the D\&T QA Program.

- ensuring compliance with all applicable regulations and requirements pertaining to D\&T activities, and appropriate state and local laws; and

- exercising the authority and responsibility to stop unsatisfactory work such that cost and schedule do not override environmental, safety, health or quality considerations.

\subsubsection{D\&T Project Technical Manager}

The Technical Manager reports to the LLNL Manager, FMDP, and has overall day to day responsibility for the planning, resources, and execution of the D\&T activities through direction and management of the D\&T Participating Organizations. This position is responsible for approving this QAPD and for maintaining an organizational structure and environment conducive to the effective implementation of the D\&T QA Program.

Specific responsibilities include:

- interface with the DOE OFMD organization with regard to overall D\&T objectives and strategies;

- establishing and implementing policies, plans, and procedures that control the quality of work;

- defining quality, developing appropriate plans to attain quality, providing support of the workers in pursuit of quality, and ensuring quality achievement; 
- submittal of this QAPD and the Implementation Matrix to DOE OFMD for concurrence;

- ensuring that adequate technical and QA training are provided for personnel performing activities important to the satisfaction of D\&T objectives;

- ensuring compliance with all applicable regulations and requirements pertaining to D\&T activities, and appropriate state and local laws;

- ensuring that personnel adhere to procedures for the development, identification, control, and protection of QA records, which includes licensing information and data;

- reviewing and approving participating Lab QAPDs and Implementing Matrices and

- identifying, investigating, reporting, and correcting quality problems.

\subsubsection{TPO QA Program Manager}

The TPO QA Program Manager reports to the LLNL Manager, FMDP, and has the authority and the responsibility to assess the effective implementation of the D\&T QA Program. Additional authorities and responsibilities of the TPO QA Program Manager include the following:

- scheduling and conducting QA audits and surveillances;

- maintaining liaison with Site QA Representatives and other affected organizations;

- preparing, as appropriate, and reviewing internal procedures that implement the provisions of this QAPD;

- reviewing and approving participating Laboratory QAPDs and Implementing Matrices;

- tracking, performing trend analysis, and reporting quality problem areas;

- providing for the processing of documentation concerning conditions adverse to quality; 
- interface with DOE OFMD Quality Assurance on matters affecting the D\&T Quality Assurance Program; and

- developing, maintaining and approving this QAPD.

The TPO QA Program Manager will have direct access to responsible management at a level where appropriate action can be affected. The TPO QA Manager will be sufficiently independent from cost and schedule considerations, have the organizational freedom to effectively communicate with senior management, and have no other responsibilities unrelated to the quality assurance program that would prevent full attention to quality assurance matters.

The TPO QA Program Manager and staff have sufficient authority, access to work areas, and organizational freedom to identify quality problems, recommend solutions, verify implementation of solutions, and assure that unsatisfactory conditions are controlled until proper disposition has occurred.

\subsubsection{TPO Planning and Support Staff}

The Technical Project Office Planning and Support Staff at LLNL are responsible for:

- developing and maintaining the D\&T QA Records Management System;

- developing and maintaining the D\&T Document Control System;

- developing and maintaining the D\&T Correspondence Control System;

- developing and maintaining the Integrated D\&T Plan and annual operating plans for DOE/MD review and concurrence;

- developing activity budget proposals for DOE/MD and tracking of expenditures; and

- auditing technical progress against the Integrated D\&T Plan and Annual Operating Plans.

\subsection{Interfaces}

The successful deployment of technologies from the D\&T effort on the schedule set by the FMDP Program Schedule Baseline for the Plutonium Immobilization 
Project, will require strong cooperation and close coordination among the D\&T team, the architect-engineer ( $\mathrm{AE})$, the plant operations team, and several DOE organizations.

The DOE OFMD is the primary interface with the D\&T TPO. DOE OFMD has overall responsibility for managing the PIP and the D\&T effort. DOE OFMD provides program and QA direction to the D\&T TPO. Two other DOE organizations provide important program information, regulations, or materials to the D\&T and the PIP through the DOE OFMD. These are the Department of Energy Office of Environmental Management (DOE-EM) and the Department of Energy Office of Civilian Radioactive Waste Management (DOE RW).

The DOE-EM program is responsible for the management and stabilization of many of the plutonium feed materials destined for immobilization. DOE-EM also manages the program responsible for operation of the Defense Waste Processing Facility, which will be a major component in the immobilization of surplus plutonium.

DOE-RW manages the DOE program for the disposal of spent nuclear fuel and high level radioactive waste in the proposed geologic repository at Yucca Mountain. The immobilized plutonium form will be one of several waste forms expected to be emplaced in the repository. The immobilized plutonium form must meet licensing and qualification requirements for geologic disposal. 


\section{FIGURE 1 \\ PLUTONIUM IMMOBILIZATION PROJECT}

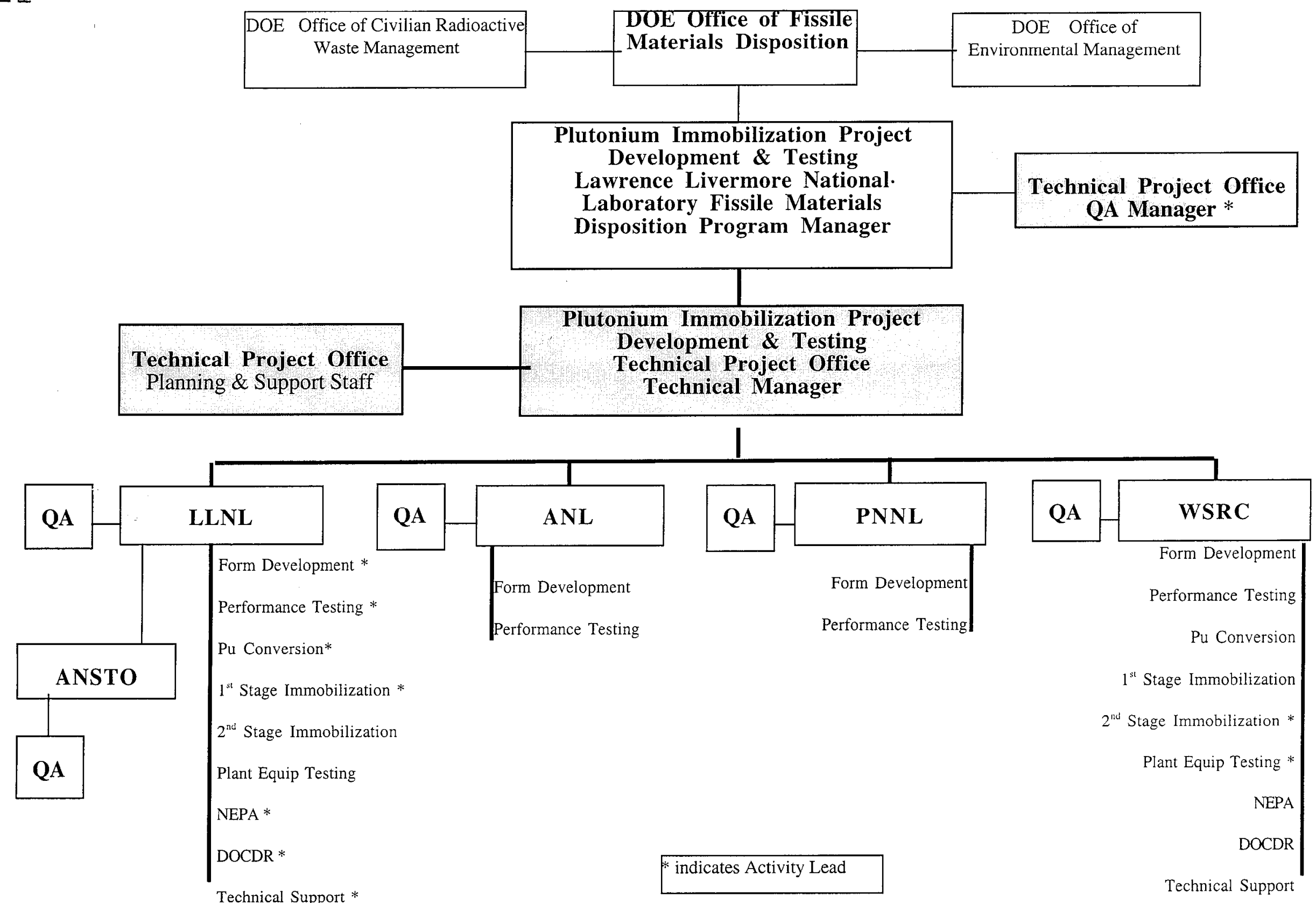


PIP-98-023

Revision 3

\subsection{QUALITY ASSURANCE PROGRAM}

\subsection{General}

This Quality Assurance Program Description applies to the D\&T Technical Project Office activities. Each participating site in the Development and Testing effort shall write and follow a tailored Quality Assurance Program Description. These QA programs are based primarily on the DOE Quality Assurance Requirements Document for the Fissile Materials Disposition Program (FMDP QARD) and the DOE/RW 0333P Quality Assurance Requirements and Description Document for the Civilian Radioactive Waste Management Program. 10 CFR Part 60, Subpart G, Quality Assurance and 10 CFR 830.120, Quality Assurance Requirements, have also been used in the development of this document. Consequently, as these documents are revised, they will be evaluated for impact and applicability to the D\&T QA Program.

This section of the QAPD describes the QA implementation requirements for planning and maintaining the QA Program. It also describes the requirements for related topics such as planning, indoctrination and training, qualification of assessment personnel, quality improvement and trending. The reason for this is to assure that QA activities are performed under controlled conditions, including the use of appropriate equipment, that individuals are trained, and that prerequisites for a given activity have been satisfied.

This QAPD is applicable to the TPO personnel performing work under the Plutonium Immobilization Project Development and Testing effort and is based principally on the $\mathrm{QA}$ requirements given in the following documents:

- DOE/FMDP Quality Assurance Requirements Document (FMDP QARD).

- DOE/RW-0333P, Quality Assurance Requirements and Description.

- 10 CFR Part 60, Subpart G, Quality Assurance.

- 10 CFR Part 830.120, Quality Assurance Requirements.

The TPO QA Program Manager reviews revisions to the above documents and makes recommendations on incorporation of changes to the TPO QAPD and Participating Laboratory QA documents, as appropriate. 


\subsection{Quality Assurance Program Documents}

The Technical Project Office has established this Quality Assurance Program Description that is applicable to the scope of work and that integrates the requirements of DOE FMDP QARD, DOE/RW-0333P and 10 CFR 830.120 into D\&T work processes. The development of a structured system of quality assurance implementing documents that meet these integrated requirements:

- provides for top down implementation of requirements or, if stipulated in procurement documents, work to the quality assurance implementing documents of the next-higher-level organization.

- accommodates the size and location(s) of the organization, the organizational structure, and the nature of the work such that management processes are carried out efficiently and effectively.

- provides positive control over external interfaces between organizations and internal interfaces within an organization. An interface exists when one organization prescribes an activity or requirement to, or shares an activity or requirement with, another organization.

\subsection{Surveillances}

Surveillances are conducted to evaluate the quality of selected D\&T activities. Surveillances are conducted to verify the quality of work in progress; to identify conditions adverse to quality; to ensure that prompt corrective action is taken by management responsible for performing the work; and to verify the timely implementation, adequacy, and effectiveness of corrective action.

The TPO QA Program Manager will conduct surveillances and document the results in a report to management in accordance with TPO Quality Implementing Procedure TQIP 18.2 QA Surveillances. This procedure requires that surveillances be performed by personnel who are knowledgeable about, and not directly responsible for, the work under surveillance.

\subsection{Management Assessments}

The LLNL Manager, FMDP, ensures that management assessments are conducted by personnel outside the quality assurance organization on an annual basis. The purpose of these management assessments is to evaluate:

- the adequacy of the resources and personnel provided to achieve and assure quality, and 
- the adequacy and effectiveness of the quality assurance program.

Management Assessments will conducted in accordance with TPO QA Implementing Procedure TQIP 2.2 - Management Assessments.

\section{$2.5 \quad$ Graded Approach}

A graded approach to the application of Quality Assurance is applied to D\&T activities. This ensures adequate programmatic controls where required and maintains a cost-effective level of implementation. Because the TPO will not directly perform quality affecting development and testing activities, the implementation of the graded approach will be performed at the participating laboratory level. However, the TPO will provide input and grading recommendations to each participating laboratory.

\subsection{Document Review}

Documents are reviewed by the affected organizations to specified requirements. The TPO will only generate the following types of documents because most of the work performed by the D\&T is delegated to the Participant Laboratories: QA Procedures, Planning and Policy documents, and consolidated reports. The TPO will conduct document reviews in accordance with TPO QA Implementing Procedure TQIP 6.2, Document Review. The implementation of this procedure will ensure that the following requirements are met:

- Review criteria are established before performing the review. These criteria consider applicability, correctness, completeness, accuracy, and compliance with established requirements.

- Pertinent background information or data are made available to the reviewers by the organization requesting the review if the information is not readily available to the reviewer.

- The review is performed by individuals other than the originator.

- Reviewers are technically competent in the subject area being reviewed.

- The scope of the review considers all aspects of the document.

- Comments resulting from the review are documented and resolved before approving the document. 


\subsection{Quality Assurance Program Information Management}

The TPO QA shall establish and maintain a quality assurance information system to facilitate effective communication of the status of the quality assurance program; status of resolution of issues, trends, and significant conditions adverse to quality; and summary of quality assurance overview results.

The TPO QA will request that each Site QA Representative provide quality assurance program information as QA status documents are issued. These documents consist of Audit Reports, Surveillance Reports, Nonconformance Reports, Corrective Action Reports, Status Reports and similar documents.

The TPO QA will consolidate and summarize the participant information and report to project management, on a monthly basis, information related to the status of the QA program.

\subsection{Personnel Indoctrination, Training, and Qualification}

TPO personnel shall be indoctrinated and trained commensurate with the position requirements. This includes indoctrination with the appropriate codes and standards, QA requirements documents, this QAPD, and applicable implementing procedures or documents.

The TPO QA will conduct indoctrination and training of TPO personnel in accordance with TPO QA Implementing Procedure TQIP 2.1, Personnel Training and Qualification.

\subsection{Implementation Matrix}

The TPO QA Manager will develop a comparison matrix of TPO QA procedures to RW 0333P QA requirements. This comparison matrix will be submitted to DOE for their review. The TPO QA Manager will review Participating Laboratory Matrices to ensure they are compliant with RW-0333P QARD requirements.

\subsection{DESIGN CONTROL}

The TPO will not directly perform any design activities. Design activities, if any, will be performed by Participant Laboratories in accordance with their QA Programs. Therefore, the TPO will not develop any procedures nor implement any of the QARD requirements for this Design Control criterion. 


\subsection{PROCUREMENT DOCUMENT CONTROL}

The TPO has limited responsibility in the area of Procurement. The TPO may process quality affecting procurement documents to subcontractors who may perform management assessments, audits, peer reviews, and other consulting or review services. These procurements will be processed through the LLNL procurement process and controlled in accordance with LLNL Quality Implementing Procedure LQIP 4.1, Procurement Document Control. The passing of technical and QA requirements to Participating Laboratories is coordinated with DOE OFMD and processed by generation of financial plans, test plans, and the Annual Operation Plan (AOP).

\subsection{IMPLEMENTING DOCUMENTS}

A program is in place which ensures that work identified as being important to meeting the requirements of the FMDP QARD is prescribed by, and performed in accordance with, written implementing documents.

The TPO will develop QA Implementing Procedures in accordance with TPO QA Implementing Procedure TQIP 5.1 Preparation, Revision, and Approval of Quality Plans and Implementing Procedures. The TPO will review applicable documents in accordance with TPO QA Implementing Procedure TQIP 6.2, Document Review. These implementing procedures will be modified versions of the existing LLNL QA Implementing Procedures.

\subsection{DOCUMENT CONTROL}

This section describes the program that ensures that D\&T documents, including changes thereto, are reviewed for adequacy, approved for release, and distributed to and used at the location where the work is being performed.

Documents and changes to documents that specify technical requirements, quality requirements or prescribe work are reviewed for adequacy, correctness, and completeness, according to the requirements of Section 5.0, prior to approval and issuance.

The distribution and use of documents, including changes and editorial corrections to documents, is controlled.

The TPO document control activities shall be performed in accordance TPO QA Implementing Procedure TQIP 6.1, Document Control. 


\subsection{CONTROL OF PURCHASED ITEMS AND SERVICES}

The TPO has limited responsibility in the area of Control of Purchased Items or Services. The TPO may process quality affecting procurement documents to subcontractors who may perform management assessments, audits, peer reviews, and other consulting or review services. The receipt of these services will be processed through the LLNL procurement receiving review process and controlled in accordance with LLNL Quality Implementing Procedure LQIP 7.1, Receiving Review.

\subsection{IDENTIFICATION AND CONTROL OF ITEMS}

The TPO will not be controlling any items at the TPO level; therefore, implementation of this QA criterion will not be implemented by the TPO. Implementation of these QA requirements may be performed by the Participating Laboratories.

\subsection{CONTROL OF SPECIAL PROCESSES}

The TPO has not identified any special processes that will be performed by personnel at the TPO level. Therefore, the requirements of this QA criterion will not be implemented by the TPO. However, special processes may be performed and controlled by Participating Laboratories.

\subsection{INSPECTION}

The TPO will not perform any Inspections. Any inspections of items will be performed at the Participating Laboratories.

\subsection{TEST CONTROL}

The TPO will not directly perform any tests of items. Any tests of items will be controlled by the Participating Laboratories.

\subsection{CONTROL OF MEASURING AND TEST EQUIPMENT}

The TPO will not use Measuring and Test Equipment at the TPO level.

Therefore, the only controls related to this Control of Measuring and Test

Equipment QA criterion are at the Participating Laboratories. 


\subsection{HANDLING, STORAGE AND SHIPPING}

The TPO will not control items for Handling, Storage and/or Shipment. Any controls to address this Handling, Storage and Shipment QA criterion will be addressed by Participating Laboratories.

\subsection{INSPECTION, TEST AND OPERATING STATUS}

The TPO will not be performing any inspection, testing, or operation of items during the D\&T effort. Therefore, any controls needed related to Inspection, Test and Operating Status will be addressed by Participating Laboratories.

\subsection{NONCONFORMANCES}

The TPO will not directly control items or equipment during the D\&T effort. The appropriate Participating Laboratory will control Nonconforming conditions for any applicable items or equipment.

\subsection{CORRECTIVE ACTION}

\subsection{CONDITIONS ADVERSE TO QUALITY}

This section describes the program for identifying and correcting conditions adverse to quality in the D\&T activities.

A condition adverse to quality is identified when a FMDP QARD or an implementing document requirement is not met. Conditions adverse to quality are classified in regard to their significance, and corrective actions are taken accordingly. Two categories of classification are established:

- Conditions Adverse to Quality, and

- Significant Conditions Adverse to Quality.

All Conditions Adverse to Quality are documented on a Corrective Action Report and reported to the appropriate levels of management responsible for the conditions. Responsible management investigates and documents the investigation of the adverse condition. Upon identification or validation of the Condition Adverse to Quality, the classification category of the condition is determined. The category can be identified as a Condition Adverse to Quality or for more serious conditions as a Significant Condition Adverse to Quality. The quality assurance organization concurs with the classification and any 
proposed corrective action to ensure that quality assurance program requirements are satisfied.

TPO QA Manager will evaluate and control Conditions Adverse to Quality in accordance with TPO QA Implementing Procedure TQIP 16.1 Conditions Adverse to Quality.

\subsection{TRENDING}

The TPO QA establishes criteria for determining adverse quality trends. Reports of surveillance results and conditions adverse to quality are evaluated to identify adverse quality trends and help identify root causes. Trend evaluation is performed in a manner and at a frequency that provides for prompt identification of adverse quality trends. Identified adverse trends are reported to the organization responsible for corrective action. Trending will be performed in accordance with TPO Quality Implementing Procedure TQIP 16.1 Trending.

\subsection{QUALITY ASSURANCE RECORDS}

\subsection{GENERAL}

A program for ensuring that records important to the D\&T effort are controlled and maintained has been established in the form of the Plutonium Immobilization Project Records Management Plan. The Plan covers the processing of D\&T Project, Administrative Records and QA Records. Administrative Procedures control the processing of all D\&T Records. These Administrative Procedures require QA Records to be handled in accordance with a QA Implementing Procedure. TPO personnel will control, protect, and submit QA Records to the D\&T Document Control Center in accordance with TQIP-17.1, QA Records.

\subsection{AUDITS}

\subsection{GENERAL}

A program for performing internal quality assurance audits to verify compliance with and to determine the effectiveness and adequacy of, the quality assurance program is established. Audits will be both compliance and performance based to ensure proper program implementation and that quality products are being delivered. Since the participating Labs are partners in the D\&T, these audits will be considered to be internal audits. An audit schedule is developed annually and revised as necessary to ensure that coverage is maintained current. 
Audits shall be performed in accordance with TPO QA Implementing ProcedureTQIP-18.1 - Audits. Auditors shall be qualified and Lead Auditors certified in accordance with TPO QA Implementing Procedure TQIP 18.2 Auditor/Lead Auditor Certification.

\section{SUPPLEMENT I SOFTWARE}

The TPO has no plans to develop any software programs for the processing of quality affecting data. Spreadsheets (with no calculations) and word processors are exempt from software QA requirements. Therefore, the TPO will not implement any of the QAPD requirements for this QA criterion. Implementation of these requirements will be performed by the Participating Laboratories.

\section{SUPPLEMENT II SAMPLE CONTROL}

The TPO will not process any samples; therefore, will not implement this Sample Control QA Criterion. However, Sample Control scope and QAPD requirements will be implemented by the Participating Laboratories.

\section{SUPPLEMENT III SCIENTIFIC INVESTIGATION}

The TPO will not be performing any scientific investigation at the TPO level. Scientific Investigations will be conducted and documented at the participating sites. However, some reports that document the results of scientific investigations performed by several Participating Laboratories may be consolidated or compiled at the TPO level. These reports and supporting documentation will be reviewed in accordance with procedures generated to comply with QA criteria 5 and 6 .

\section{SUPPLEMENT IV FIELD SURVEYING}

The TPO will not perform any activities related to Field Surveying. Field Surveying controls are generally applicable to the D\&T effort.

\section{SUPPLEMENT V CONTROL OF ELECTRONIC MANAGEMENT OF DATA}

The TPO will not be the controlled source for information that will be used in design analysis, process control, or scientific investigation. Sources of data for these purposes will be controlled by Participating Laboratories. 


\section{APPENDIX A HIGH-LEVEL WASTE FROM PRODUCTION}

This section of the 0333P QARD contains amplifications of requirements defined in other QA criteria. Implementation of these requirement amplifications will be addressed by the TPO through project planning documents, activity planning documents, and Implementing Procedures. The amplifications relate to QA criterion 2 - QA Program and Supplement III - Scientific Investigations for the conduct of readiness reviews, the control of technical modifications, and the evaluation of development and qualification results.

\section{APPENDIX B STORAGE AND TRANSPORTATION}

The TPO does not have any activities related to storage casks, transportation casks, multi-purpose canisters, nor ancillary equipment during the Development and Testing effort. Therefore, there are no QA controls related to this Storage and Transportation Appendix at the TPO level during the D\&T effort.

\section{APPENDIX C MINED GEOLOGICAL DISPOSAL SYSTEM}

The TPO has no specific activities related to the Mined Geological Disposal System. This Appendix contains modifications to some of the QA criteria and their related requirements listed in this QAPD. The requirements of this Mined Geological Disposal System Appendix will be included in Participating Laboratory QAPDs and QA Implementing Documents, as applicable. 